\title{
MAPPING VIS AND UVL IMAGERY ON 3D GEOMETRY FOR NON-INVASIVE, NON- CONTACT ANALYSIS OF A VASE
}

\author{
E. Nocerino ${ }^{\text {a,b,c }}$ *, D.H. Rieke-Zapp ${ }^{\text {d }}$, E. Trinkl ${ }^{\text {e }}$, R. Rosenbauer ${ }^{\mathrm{f}}$, E. M. Farella ${ }^{\mathrm{a}}$, D. Morabito ${ }^{\mathrm{a}}$, F. Remondino $^{\mathrm{a}}$ \\ a 3D Optical Metrology (3DOM) unit, Bruno Kessler Foundation (FBK), Trento, Italy - (nocerino, elifarella, morabito, \\ remondino)@fbk.eu \\ b LSIS, I\&M Team, Aix-Marseille Universite, Polytech Luminy, Marseille, France - erica.nocerino@univ-amu.fr \\ c Theoretical Physics, ETH Zurich, Zurich, Switzerland - erican@ phys.ethz.ch \\ ${ }^{\mathrm{d}}$ Hexagon, Scanner Innovation Center, Meersburg, Germany - dirk.rieke-zapp@ hexagon.com \\ e Institute of Archaeology, University of Graz, Graz, Austria - elisabeth.trinkl@uni-graz.at \\ ${ }^{\mathrm{f}}$ ALPA Capaul \& Weber Ltd., Zürich, Switzerland- ralph@alpa.ch
}

Commission II, WG II/8

KEY WORDS: Ultraviolet-induced luminescence, multispectral imaging, 3D modelling, non-invasive analysis, fringe projection, photogrammetry, dense matching, cultural heritage

\begin{abstract}
:
The paper presents an investigation about the combination of multispectral and 3D imaging aiming at the analysis of the condition and preservation of an ancient vase. Visible-reflected (VIS) and -induced luminescence (UVL) images are mapped to 3D models produced with image- and range-based 3D modelling techniques. The case study is an Attic vase, part of the pottery collection of the Landesmuseum Rudolfinum (Carinthia, Austria) and temporarily stored in the Institute of Archaeology of the University of Graz, Austria. The aim of this study is to exploit the added-value provided by mapping multispectral imaging onto 3D geometry for a comprehensive knowledge of the condition of a restored Cultural Heritage $(\mathrm{CH})$ item.
\end{abstract}

\section{INTRODUCTION}

Non-invasive, non-contact digitization techniques are widely used in the Culture Heritage $(\mathrm{CH})$ community, allowing for several applications, such as (i) documenting the state of $\mathrm{CH}$ assets; (ii) performing qualitative, quantitative and comparative analyses; (iii) planning conservation and preservation strategies; (iv) visualization, communication and dissemination.

A general distinction can be made between techniques which aim at acquiring and reproducing the geometry of the $\mathrm{CH}$ asset, and methods that primarily focus on the identification and characterization of material components.

Traditionally, 3D scanning and photogrammetry fall in the first category, while technical photography (TP) or multispectral imaging is mainly intended for art diagnostics, hence for gathering information about the different components making up an object.

Multispectral imaging entails the acquisition of photographs using a broad range of wavelengths, including and extending the visible part of the electromagnetic spectrum. This method comprises two main categories: reflectance (or reflected radiation) and luminescence (emitted light or photo-induced luminescence).

The most frequently used reflectance imaging techniques are visible-reflected (VIS or VISR, corresponding to standard photography, i.e. the acquisition of RGB colour information), infrared-reflected (IRR) and ultraviolet-reflected (UVR), while luminescence imaging methods include ultraviolet-induced luminescence with emission in the visible range (UVL or UIL), visible-induced visible luminescence (VIVL) and visibleinduced infrared luminescence (VIL) (Dyer et al., 2013). VIS corresponds to standard photography: images are generated using visible radiation and collecting the reflected light in the visible region. It hence provides reference images to interpret images produced from other multispectral techniques. a)
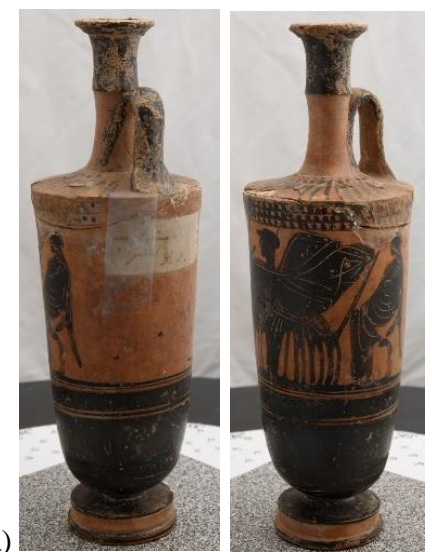

b)

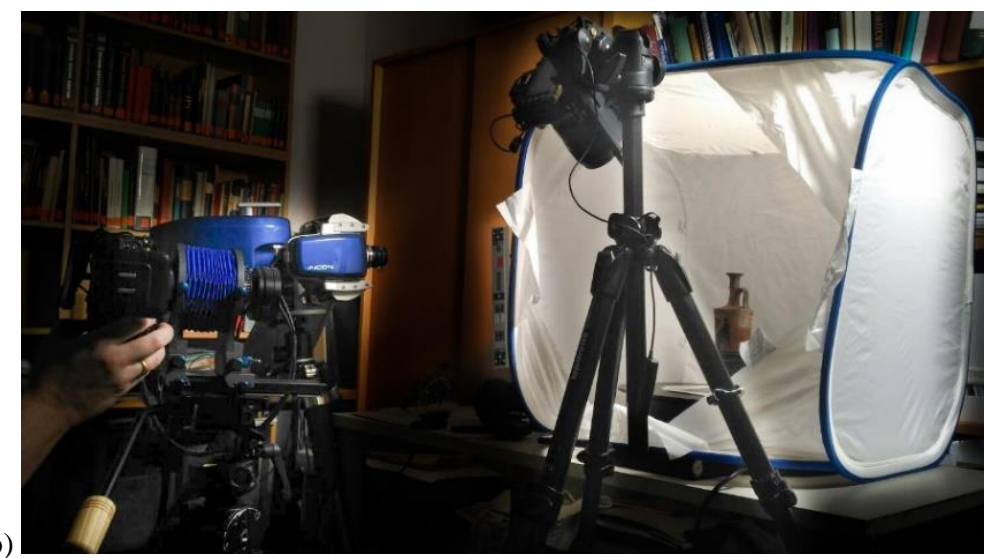

Figure 1. The Attic vase used in the investigation (a) and the acquisition set-up with a fringe projection scanner and two digital cameras (b). 


\subsection{Paper contribution}

This work presents the combination of UVL and VIS imaging with 3D modelling, applied to an Attic vase, part of the pottery collection of the Landesmuseum Rudolfinum (Carinthia, Austria) and temporary stored at the Institute of Archaeology of the University of Graz, Austria. The aim of this investigation is to exploit the added-value provided by mapping multispectral imaging onto 3D geometry for a comprehensive knowledge of the condition of a restored $\mathrm{CH}$ item.

A Greek figured pottery, named 'vase' or 'vessel' according to the classical archaeology nomenclature (Figure 1a) is selected as case study. Indeed, the vase presents several breakages and has undergone restoration work over time, reasons that pushed to authors to use it as case study.

In this paper, acquisition and processing steps of the employed techniques are provided. Analyses on the multispectral imagery mapped on the geometry are also presented to show the potentialities of the employed approach, which provides a more profound perception about the vase's actual state of preservation. The possibility to link the radiometric information of a detail with its spatial position on the geometry, represents a valuable tool for a proper conservation of vases, as well as for any restored $\mathrm{CH}$ asset.

\section{NON-INVASIVE, NON-CONTACT TECHNIQUES}

\subsection{Techniques for digitization of 3D geometry}

The most common techniques for 3D geometry digitization in the $\mathrm{CH}$ field are 3D scanning, also known as range imaging, and photogrammetry. When a proper acquisition planning and execution is carried out, the two techniques are able to provide high quality results (Beraldin et al., 2011; Douglass et al., 2015; Remondino, 2011). Critical and limiting factors that may negatively affect the produced outcomes have been deeply investigated (Barsanti et al., 2014; Menna et al., 2016; Remondino et al., 2013). To overcome their individual weakness, it is common practice to integrate the two approaches (Fassi et al., 2011; Guidi et al., 2009; Lerma et al., 2010; Nex and Rinaudo, 2011).

In the present study, both 3D scanning and photogrammetry were employed, with the aim to show how both the techniques can provide the geometry where to map the texture information derived from the multispectral imaging.

\subsection{Multispectral imaging}

Multispectral imaging requires three main components (Dyer et al., 2013): (i) a radiation source emitting light in the desired wavelengths range, (ii) the object, whose surface materials interacts with the incoming light, (iii) the outgoing radiation, produced by the previous interaction and recorded by a digital camera. The interaction between the incoming light depends on the wavelength of the emitted source and the material on the object; it can be of three different forms: (i) absorption, (ii) reflection, and (iii) absorption and re-emission as luminescence at longer wavelengths (Dyer et al., 2013). Consequently, multispectral imaging provides clues about different materials, for example: IRR can identify carbon or lead-based underdrawings; UVR can reveal the presence of, for example, superficial organic coatings and pigments or iron gall ink; UVL can map organic materials, such as binders, coatings or consolidating material; VIL can capture the luminescence from pigments, such as the Egyptian blue and cadmium-based colourants (Verri and Saunders, 2014).

UVL consists in using UV radiation to excite electrons in the atoms composing a material, which release light in the visible region of the spectrum. The light emission produced depends on many factors, including the wavelength and bandwidth of the UV source, as well as the chemical composition and aging of the material. UVL has been widely used for the analysis of $\mathrm{CH}$ objects, especially for paintings and also pottery, where it is mainly exploited for the preliminary identification of pigments (Cosentino, 2015; Vak, 2013). UVL is also employed in conjunction with other TP and 3D modelling techniques, as tool for complete diagnostic analysis, including also metric evaluation of geometrical deformation (Remondino et al., 2011).

\section{CASE STUDY}

The acquisition was performed at the Institute of Archaeology of the University of Graz, Austria.

The vase was chosen because of its actual condition: it was broken and restored. Some breakages are still visible, which were partly restored and retouched. In many other cases, almost the whole surface is overworked by modern conservators, who aimed to convey the illusion of undamaged, complete object. (Bourgeois, 2007; Vak, 2013; Kästner and Saunders, 2016). The question this investigation aims to answer is how heavy the overworking was. Moreover, an exhaustive knowledge of the vase's 'health state', together with the identification of material employed for its restoration, will support a proper future conservation strategy.

\subsection{The Attic vase}

The vessel is part of the pottery collection of the Landesmuseum Rudolfinum, Carinthia, Austria (inventory number 1245).

From the Landesmuseum Rudolfinum database, any information about the donor or seller of the vase to the museum and about the place where the asset was originally found is missing. This situation is common to many objects that were acquired by the museums in the 19th century.

At that time, trade of antique objects was a very profitable business. Greek vases were ideal assets for illegal merchandising, because of their small size and lightweight, being more easily transportable and less expensive than, for example, sculptures. Their trading used to attract huge group of possible purchasers, including emperors, aristocracy normal citizens, and, especially in the late 19th century, factory-owners.

\begin{tabular}{|l|c|c|c|}
\hline & \# of scans & Lateral resolution $(\mathrm{mm})$ & Final 3D mesh resolution /level of detail $(\mathrm{mm})$ \\
\hline Fringe projection 3D scanner & 12 & 0.094 & $<0.1$ \\
\hline & \# of images & Image GSD $(\mathrm{mm})$ & Final 3D mesh resolution /level of detail $(\mathrm{mm})$ \\
\hline Photogrammetry & $108(+13$ for scaling) & $\approx 0.045$ & $<0.1$ \\
\hline
\end{tabular}




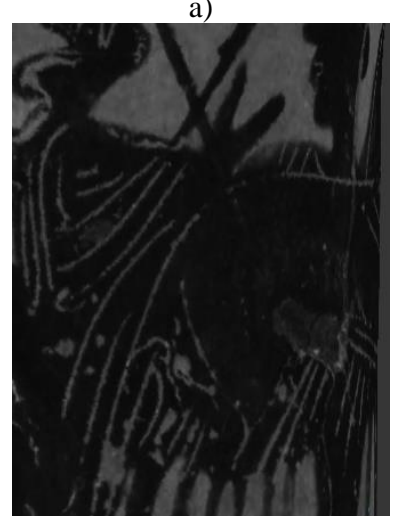

b)

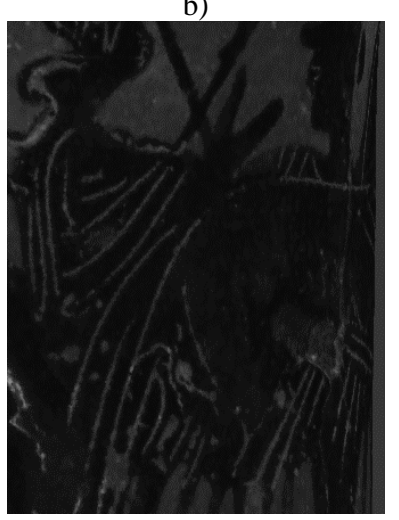

c)

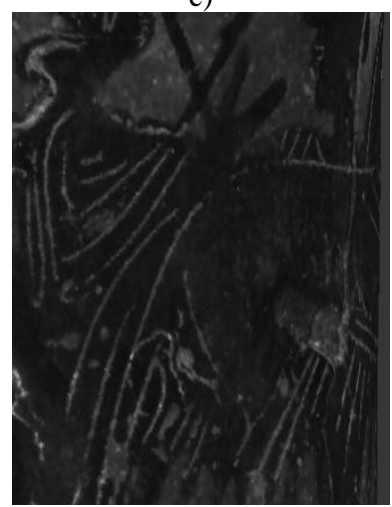

d)

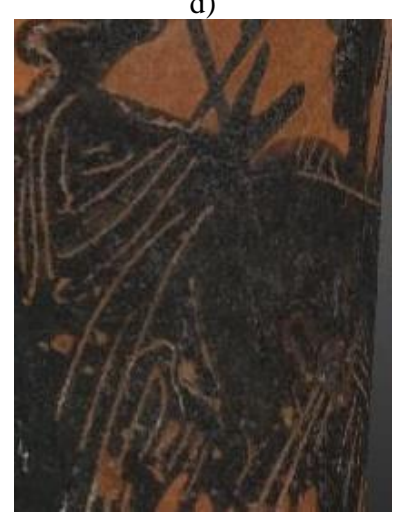

Figure 2. Detailed view of the mesh model from the 3D scanner coloured with the three separate channels R (a), G (b) and B (c), and of the photogrammetric dense point cloud with RGB information (d).

The vase's height and foot diameter measure, respectively, 206 $\mathrm{mm}$ and $69 \mathrm{~mm}$. Decorated in the so-called black-figured technique (Figure 1a), it was made in Athens in the first half of the 5 th century BC.

The picture depicts a quite common scene for vases of that epoch, i.e. a man mounting a chariot, heading to a seating woman. The shape of the vase is known as lekythos. Vases of this shape were used for scented oils, parfums (Zimmermann-Elseify 2017, 1521).

The vase shows a label, situated on the upper part of the body on the backside, near to the edge of the shoulder. It is not sure when and who affixed it; however, it is likely that the writing contains information about a former owner of the vase or the place where the asset was found.

A tape, joining together the upper and lower parts of the vase, runs vertically across the label, which ends at the same line as the left edge of the tape. It may be argued that originally the label extended further to the left, because the writing begins right at the edge of the label, meaning that the left part has got lost. Consequently, the original size of the label is unknown.

\section{3D DIGITIZATION OF THE VASE'S GEOMETRY}

The digitization of the vase's geometry was performed with two techniques (Table 1):

3D scanning employing a fringe projection triangulation-based system (AICON StereoScan neo)

- $\quad$ photogrammetry, with a full-frame, high-grade digital single lens reflex (DSLR) camera (Nikon D750) equipped with a fixed macro lens (AF-S Micro Nikkor $60 \mathrm{~mm} \mathrm{f} / 2.8 \mathrm{G}$ ED $60 \mathrm{~mm}$ ).

Figure $1 \mathrm{~b}$ shows the main acquisition set-up. The vase is positioned on an automatic rotating table within a box for still photography for visible light imagery. Both the fringe projection scanner and VIS/photogrammetry data were processed with semi-automatic procedures to obtain high-resolution mesh models of the vase, as described in the following sections.

\subsection{Fringe projection 3D scanning and data processing}

The 3D model of the vase was captured with a fringe projection scanner, the AICON StereoScan neo with dual 8MP monochrome cameras. The scanner setup allowed for a point spacing on the vase of approximately $0.094 \mathrm{~mm}$. Resolution in Z-direction, i.e. in the direction of the optical axis, was 0.013 $\mathrm{mm}$. The scanner projects fringe patterns with digital light projection (DLP) technology. Table 1 reports the main info of the performed acquisition and derived 3D model.

Three high-power LEDs with red, green and blue colour were used to project white light. For this project the vase was scanned with white light.

For texture mapping, the scanner recorded images under red, green and blue illumination (Figure 2a, b and c). Stacking imagery of the primary colours allowed calculation a colour composite image from the three monochrome layers. Imagery of the three individual channels was also analysed for more distinct coverage of the visible spectrum. All scanner imagery was mapped automatically on the 3D model with the AICON texture mapping add-on software. Imagery taken with other cameras can also be mapped semi-automatically with the same software tool. The resulting mesh is shown in Figure 4a.

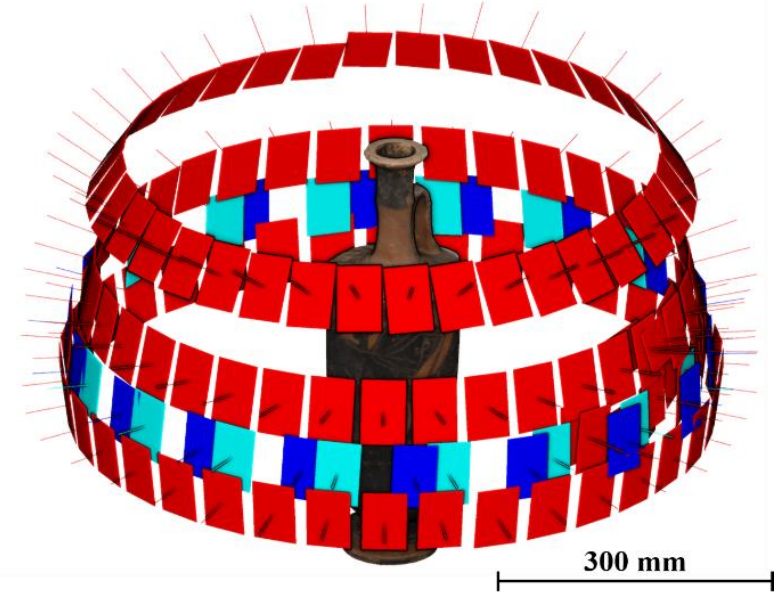

Figure 3. Computed camera networks for the various image acquisitions: VIS imagery - photogrammetry (red), UVL @ $254 \mathrm{~nm}$ (blue) and UVL@ 366 nm (cyan). 


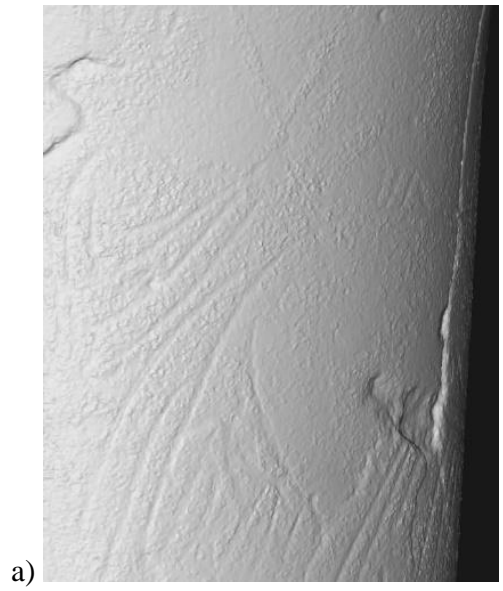

b)

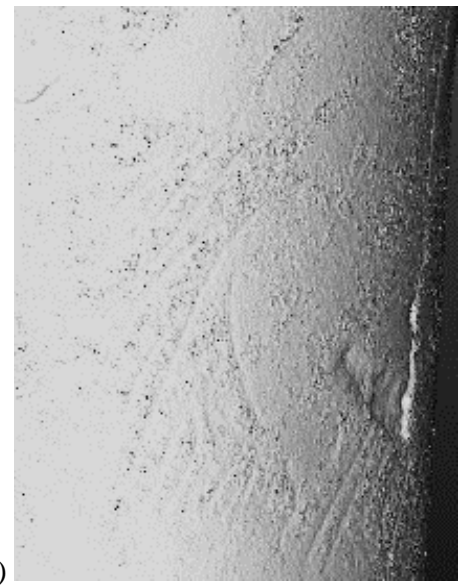

c)

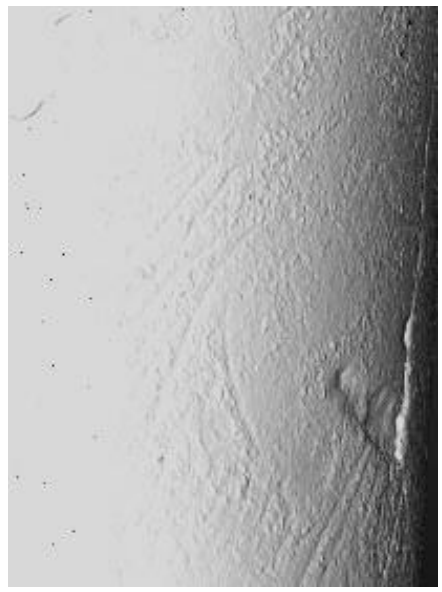

Figure 4. Shaded detailed view of the 3D scanner mesh model (a) and photogrammetric dense point cloud: after the automatic dense image matching procedure (b) and after a semi-automatic editing approach to remove the highest-frequency noise in the area with low signal-to-noise ratio (mainly dark colour) areas.

\begin{tabular}{|c|c|c|c|c|c|c|c|c|}
\hline & \multicolumn{4}{|c|}{ UVL@ @254nm } & \multicolumn{4}{|c|}{ UVL@ @366 nm } \\
\hline IMAGING SYSTEM & $\begin{array}{l}\text { \# of } \\
\text { images }\end{array}$ & $\begin{array}{l}\text { exposure } \\
\text { time }\end{array}$ & $\underset{\text { number }}{f}$ & $I S O$ & $\begin{array}{l}\text { \# of } \\
\text { images }\end{array}$ & $\begin{array}{l}\text { exposure } \\
\text { time }\end{array}$ & $\begin{array}{c}f \\
\text { number }\end{array}$ & ISO \\
\hline $\begin{array}{l}\text { Nikon D750 + AF-S Micro Nikkor 60mm } \\
\text { f/2.8G ED } 60 \mathrm{~mm}+\text { HOYA UV(0) filter }\end{array}$ & 18 & $30 \mathrm{~s}$ & 16 & 3200 & 18 & $15 \mathrm{~s}$ & 16 & 3200 \\
\hline $\begin{array}{l}\text { Ricoh Pentax K-1 + Jenoptik CoastalOpt } \\
\text { 105mm f/4.5 UV-VIS Apochromatic Macro } \\
\text { Lens }\end{array}$ & 18 & $30 \mathrm{~s}$ & 16 & 3200 & 18 & $30 \mathrm{~s}$ & 16 & 1600 \\
\hline
\end{tabular}

Table 2. Camera settings for the UVL imaging acquisition.

\subsection{VIS imagery - photogrammetry acquisition and data processing}

The main features of the photogrammetric image network are summarised in Table 1. The images were acquired at three different heights to obtain a full coverage of the asset

The images were processed using a commercial software application, i.e. Agisoft PhotoScan (2017), following a standard photogrammetric pipeline, entailing a self-calibrating bundle adjustment, with a posteriori scaling using a calibrated scale-bar. The resulting camera network is shown in Figure 3, while Figure $4 \mathrm{~b}$ reports a detailed view of the dense image matching point cloud. To reduce the effect of noise, especially in the black areas of the texture, where a low signal-to-noise ratio is expected, a semi-automatic cleaning procedure was applied to the point cloud. The filtering approach relies on point properties, such as RGB, normal vector, density, roughness, to reduce the noise generated by the employed dense image matching strategy, but, at the same time, preserving the geometry details (breakages, scratches, etc.).

The procedure was performed in CloudCompare (2017): the points were first classified according to their RGB components. Darker and brighter areas were then filtered separately, computing local roughness and density. Finally, the spatial distribution of the points was regularised adopting a voxelized grid approach (Figure 4c). From the cleaned point cloud, a mesh model with an average final resolution better than $0.1 \mathrm{~mm}$ was generated.

The mesh model from the 3D scanner was finally aligned to the photogrammetrically derived mesh model, through the iterative closest point (ICP) registration method, implemented in CloudCompare (2017).

\section{UVL IMAGERY}

UVL imagery was acquired with two photographic systems: the same used for photogrammetry, but with the lens equipped with a HOYA UV(0) filter, and a full-frame DSLR Ricoh Pentax K-1 coupled with a Jenoptik CoastalOpt $105 \mathrm{~mm}$ f/4.5 UV-VIS Apochromatic Macro Lens. The Pentax K1 was used with pixel shift mode, a feature to reduce demosaicking effect from RGB Bayer sensors. An UV lamp was used to provide two different illumination settings, respectively in the middle $(254 \mathrm{~nm})$ and near $(366 \mathrm{~nm}) \mathrm{UV}$ wavelength range, which are commonly used in TP photography for art inspection (Ultraviolet Lamp, 2018; Vak, 2013).

Table 2 contains the main camera settings adopted for the acquisition. The image number is rather low because the UVL images were acquired only for the texture mapping and analyses of the main part of the vase, while the higher number of VIS images was required for the generation of $3 \mathrm{D}$ geometry.

To avoid interference from other radiation sources, as well as from surrounding materials and colours, the environment was put in absolute darkness, with the UVL lamp as the only lighting source. To assure a homogenous illumination, the lamp was slowly moved around the vase during the very long exposure times. 

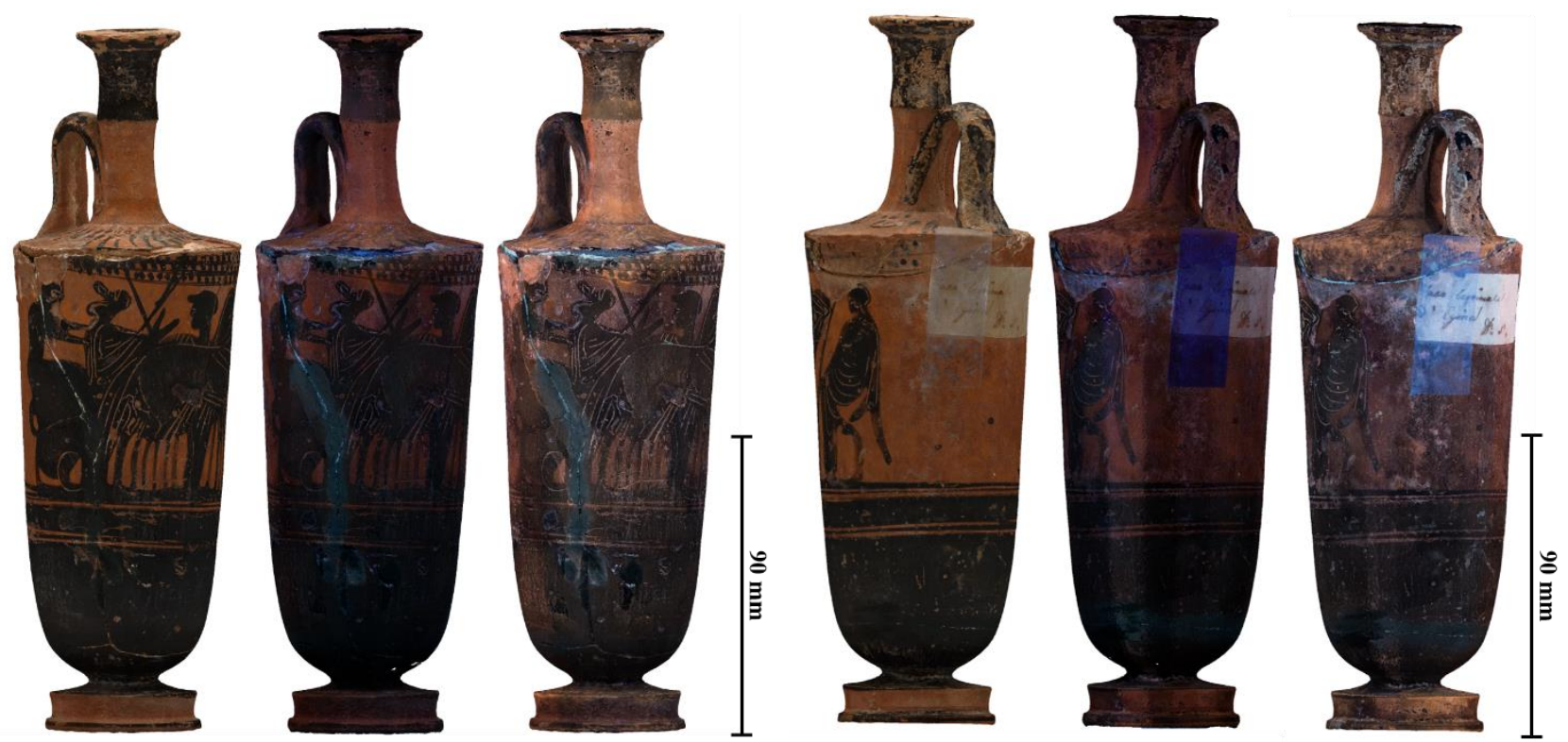

Figure 5. Photogrammetrically derived mesh model with the VIS and UVL texture mapping.

The different UVL imagery dataset were processed following an automatic photogrammetric procedure and oriented in the same coordinate reference system together with the VIS images/photogrammetry data (Figure 3). In this way, it was possible to automatically map all the multispectral data on the $3 \mathrm{D}$ geometry provided by both the 3D scanner and photogrammetry. In Figure 5 the mapping of VIS and UVL images onto the photogrammetry mesh model is shown.

From the 3D mesh model with high-resolution texture, a rollout of the figured scene was derived (Figure 6); rollout is recognised as the most convenient method to observe, analyse and interpret the depicted scene in its entirety (Mara and Portl, 2013). This 2D representation is created by 'unrolling', i.e. projecting the cylindrical body of the vessel onto a plane and preserving the geometrical relationship or mapping between the geometry and the external textures.

\section{ANALYSES}

The combination of multispectral imaging and 3D geometry offer many advantages for a thoughtful study of the vase.

First, based on the 3D model, the geometry of the asset can be investigated as a whole, while traditional 2D representation methods are usually an idealized representation of the shape. This often makes the evaluation of the potter's hand and also the identification of recent interference more difficult.

Texture mapping allows to map the acquired images on the digitised geometry, potentially exploiting the full resolution of the original images. Moreover, the localisation of elements of interest on the surface is traceable and measurable by the combination with its 3D geometry, which represents an added value for further analyses on the archaeological object.

The authors knew in advance that the vase was broken and heavily restored. The cracks are visible on the surface, the bottom is reinforced internally with a plaster lining. When cracks do not match perfectly, the common practise dictates that they are closed with an additional substance, of unknown material in the case under study. In the UV light, it is easily visible that the fill mass appears black with small sparkling white inclusions (Figure 7). This is quite unexpected: past studies on UVL methods applied on vases (Bourgeois, 2007; Vak, 2013; Kästner and Saunders 2016) report that the fill mass used in vases restored in the 19th century glows under UVL. The same should apply also the lekythos studied in the present work, but this is not the case. on the contrary, it can be easily observed that the adhesive soaked the surface along the cracks. Consequently, a chemical analysis would be necessary to determine the filling material and establish a future conservation treatment. Apart from filling and gluing cracks, contrary to our expectation the figured scenes were not altered by the former conservator (Figure 6).

The UVL images revealed interesting information written on the label (Figure 8), which were not clearly readable under normal visible light. The first word starts with a capital, meaning that not a significant portion of the left side of the label has got missing. The writing is in Italian: Vaso lagrimale / d'Egina / Dr. 5, from where it is possible to guess interesting hypotheses. Most of the vases in the museums was found in and traded via Italy, while this lekythos is originally from the Greek island Aegina and it costed 5 Drachmae. The vase is called a vaso lagrimale, i.e. a vessel for tears, term adopted in the 19th century and now replaced by lekythos (Kästner and Saunders, 2016).

\section{DISCUSSION AND OUTLOOKS}

This paper presented a promising study about the combination of multispectral and 3D imaging aiming at the analysis of the condition and preservation of an ancient vase. 
The International Archives of the Photogrammetry, Remote Sensing and Spatial Information Sciences, Volume XLII-2, 2018 ISPRS TC II Mid-term Symposium “Towards Photogrammetry 2020”, 4-7 June 2018, Riva del Garda, Italy
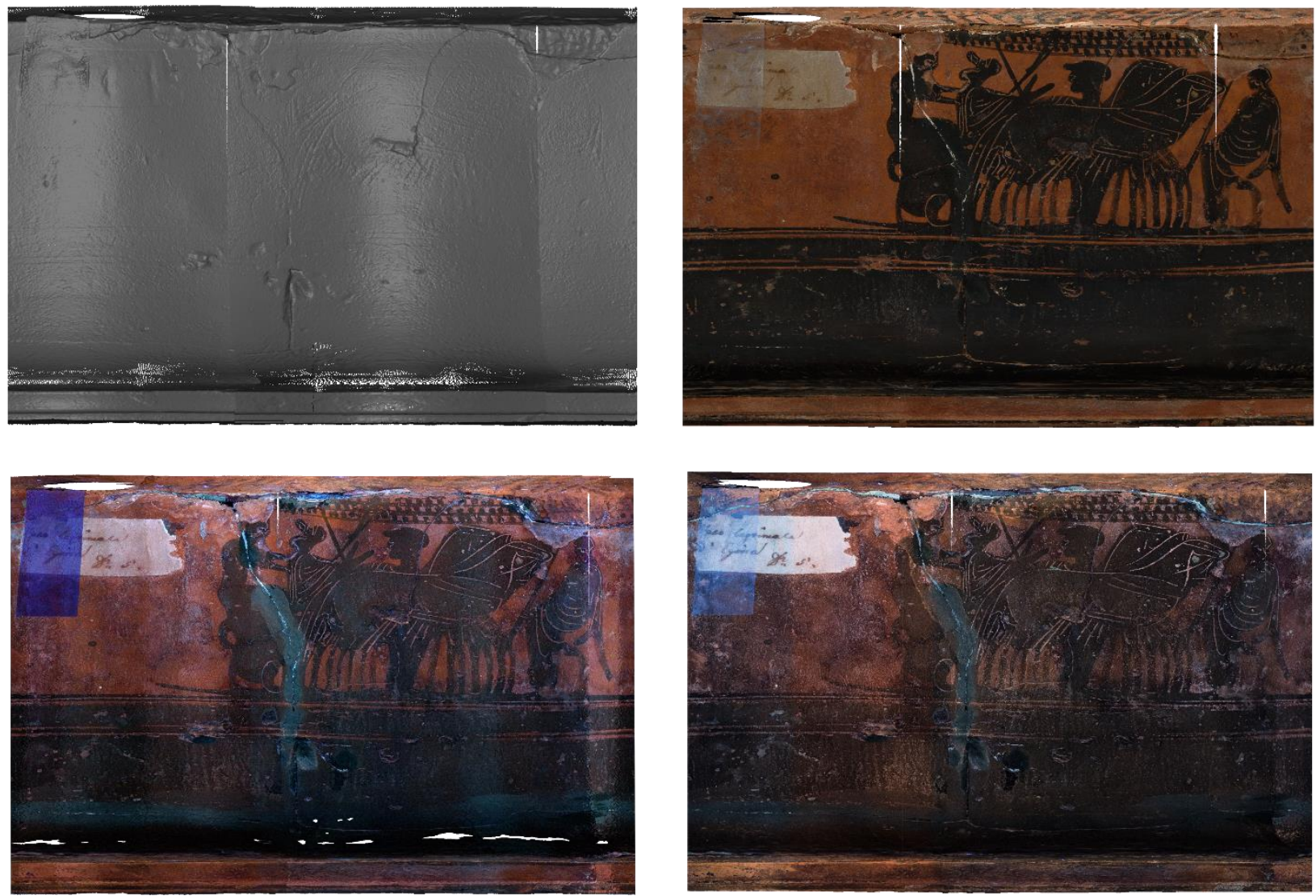

Figure 6. Rollout from the mesh model showing the geometry (a) and the three different texture mapping: VIS (b), UVL @ 254 nm (c), UVL @ 366 $\mathrm{nm}(\mathrm{d})$.
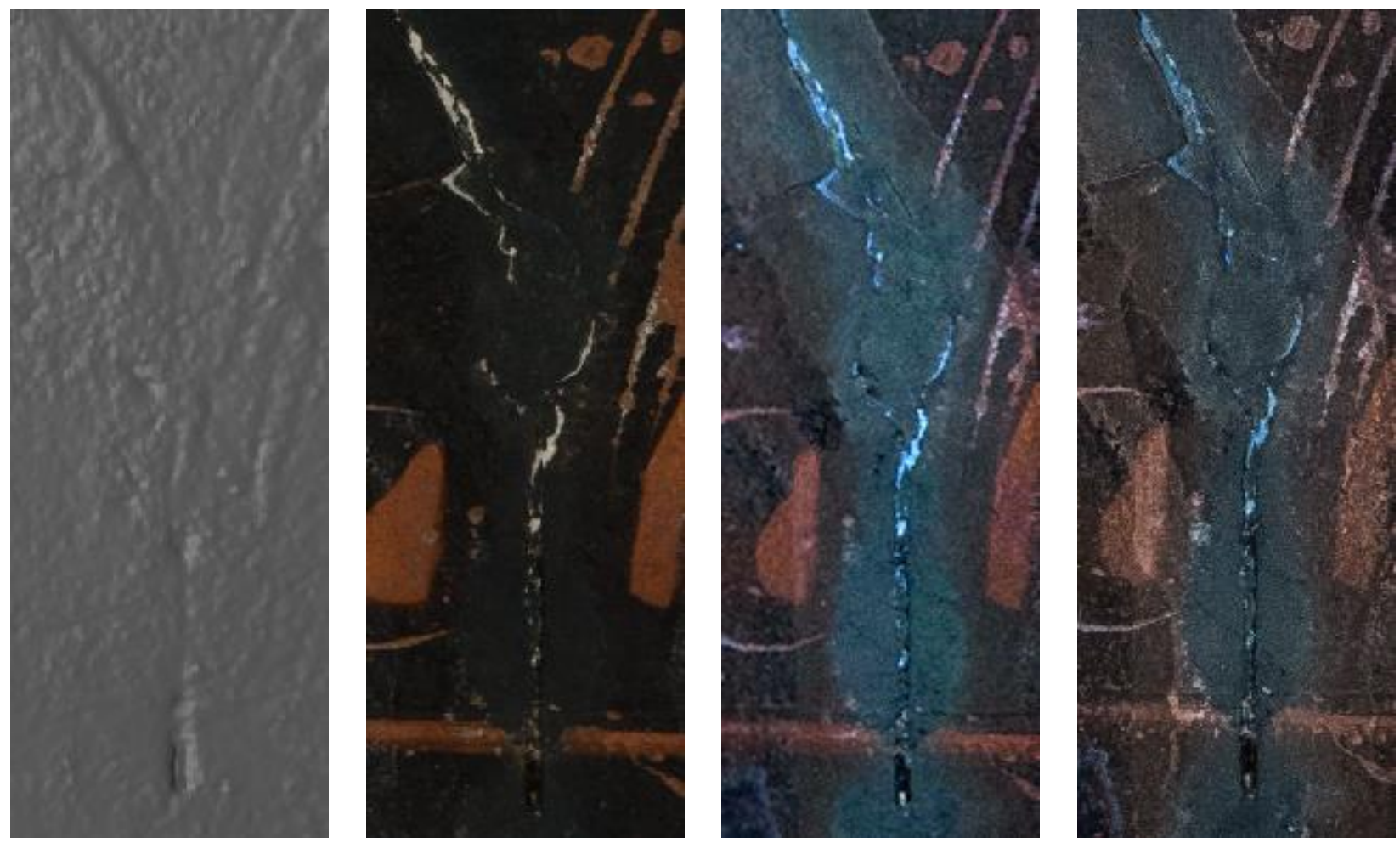

Figure 7. Detailed views of a break from the mesh model showing the geometry (a) and the three different texture mapping: VIS (b), UVL @ 254 nm (c), UVL@ 366 nm (d). 

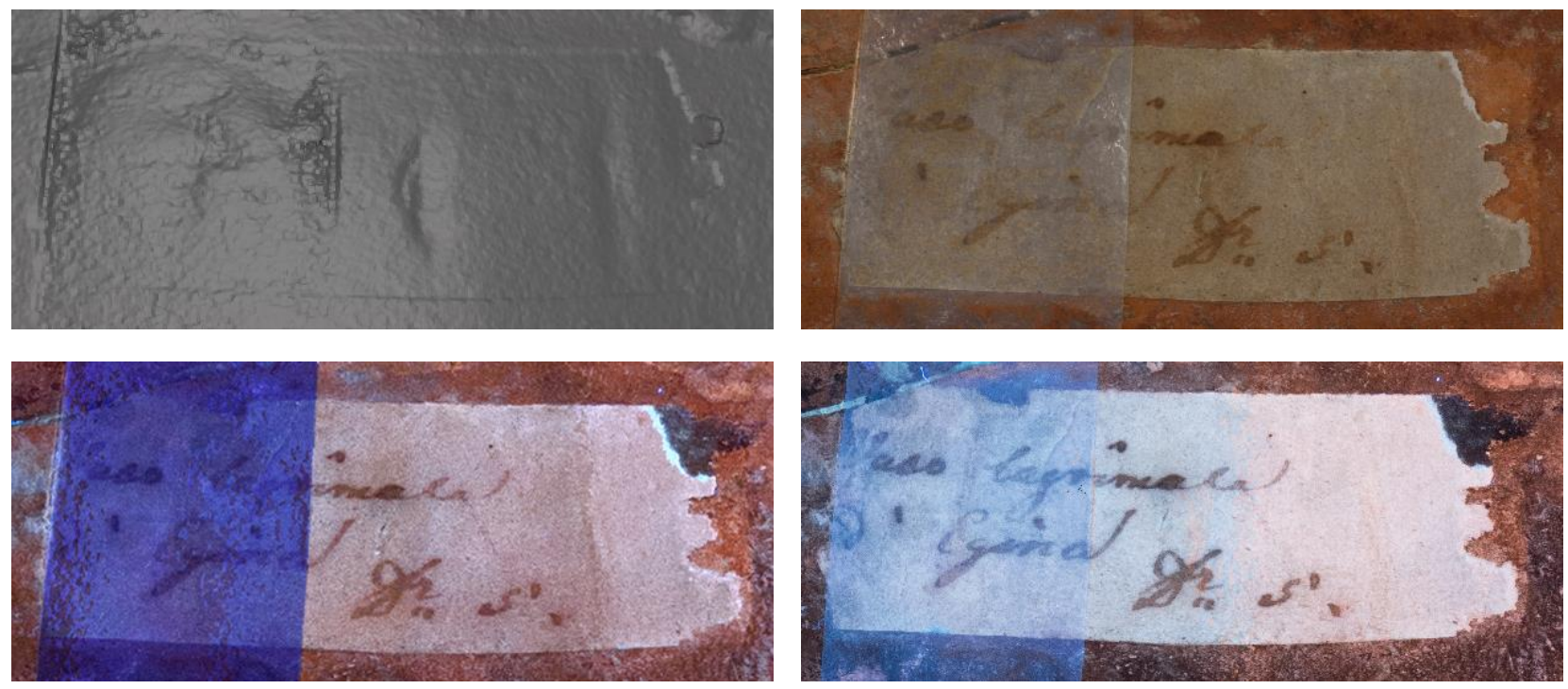

Figure 8. Detailed views of the vase label from the mesh model showing the geometry (a) and the three different texture mapping: VIS (b), UVL @ 254 nm (c), UVL@ 366 nm (d).

The geometry of the asset was digitised with both 3D scanning and photogrammetry.

The digitization approach based on the 3D scanner proved to be straightforward, allowing to check in real time the quality of the derived data. It required little human intervention in the processing step and, at the same time, provided high resolution detailed geometry (Figure 4a).

On the other hand, the photogrammetric acquisition demanded a careful planning and acquisition strategy. When the image scale is large, in this case about 1:10, the depth of field (DOF), can be very small and not enough to cover the object of interest (Nocerino et al., 2016). Consequently, the camera distance has to be accurately adjusted to better fit the object' shape. Moreover, dense image matching algorithms heavily suffer from areas with poor texture and contrast (Remondino et al., 2014) and may require a post-processing cleaning procedure to obtain noise-free data.

The use of the two different UVL wavelength did not provide meaningful different information. However, the combination of the 3D geometry and UVL showed that fill mass used in the cracks visible on the vase's surface did not match with the one expected from literature and further analyses should be undertaken for a more comprehensive understanding.

Nevertheless, standardised procedures and guidelines for a proper acquisition of multispectral imaging and the subsequent combination with $3 \mathrm{D}$ geometry digitization techniques are highly advisable. This is even more crucial when environmental conditions, such lighting, humidity, etc. are hard to be fully controlled, circumstance very common in museums.

The 3D model with VIS and UVL texture mapping are accessible on a web-viewer (http://3dom.fbk.eu/repository/visuvl_mapping/), which will serve as basis for the development of a web-based information system. Such a system will fully exploit the potentiality of the presented approach, allowing curators, scholars and researchers to access and share the generated data for further analyses and investigation.

\section{ACKNOWLEDGEMENTS}

This study was partly supported by Bernd Breuckmann Award 2016, granted to Erica Nocerino.

The authors thank Stephan Karl, Graz, for his help in deciphering the vase's label.

\section{REFERENCES}

Agisoft PhotoScan, 2017. http://www.agisoft.com/, v. 1.2.6

Barsanti, S.G., Remondino, F., Fenández-Palacios, B.J. and Visintini, D., 2014. Critical factors and guidelines for 3D surveying and modelling in Cultural Heritage. International Journal of Heritage in the Digital Era, 3(1), pp.141-158.

Beraldin, J.A., Picard, M., Bandiera, A., Valzano, V. and Negro, F., 2011, January. Best practices for the 3D documentation of the Grotta dei Cervi of Porto Badisco, Italy. In Three-Dimensional Imaging, Interaction, and Measurement (Vol. 7864, p. 78640J). International Society for Optics and Photonics.

Bourgeois, B., 2007. "Abili restauratori”. Naples and the Art of Vase Restoration. Bentz, M. and Kästner, U. (ed.), Konservierung oder Restaurieren, München, pp. 41-47.

CloudCompare, 2017. http://www.cloudcompare.org/, v. 2.9.1.

Cosentino, A., 2015. Practical notes on ultraviolet technical photography for art examination. Conservar Património, (21).

Douglass, M., Lin, S. and Chodoronek, M., 2015. The application of 3D photogrammetry for in-field documentation of archaeological features. Advances in Archaeological Practice, 3(2), pp.136-152.

Dyer, J., Verri, G. and Cupitt, J., 2013. Multispectral imaging in reflectance and photo-induced luminescence modes: a user manual. The British Museum, 7th framework program of Charisma Project. 
Fassi, F., Achille, C. and Fregonese, L., 2011. Surveying and modelling the main spire of Milan Cathedral using multiple data sources. The Photogrammetric Record, 26(136), pp.462-487.

Guidi, G., Russo, M., Ercoli, S., Remondino, F., Rizzi, A. and Menna, F., 2009. A multi-resolution methodology for the 3D modeling of large and complex archeological areas. International Journal of Architectural Computing, 7(1), pp.39-55.

Kastner, U. and Saunders, D. eds., 2016. Dangerous Perfection: Ancient Funerary Vases from Southern Italy. Getty Publications.

Lerma, J.L., Navarro, S., Cabrelles, M. and Villaverde, V., 2010. Terrestrial laser scanning and close range photogrammetry for 3D archaeological documentation: the Upper Palaeolithic Cave of Parpalló as a case study. Journal of Archaeological Science, 37(3), pp.499-507.

Mara, H. and Portl, J., 2013. Acquisition and documentation of vessels using high-resolution 3D-scanners (pp. 25-40). Verlag der Österreichischen Akademie der Wissenschaften (VÖAW).

Menna, F., Nocerino, E., Remondino, F., Dellepiane, M., Callieri, M. and Scopigno, R., 2016. 3D digitization of an heritage masterpiece-a critical analysis on quality assessment. The International Archives of the Photogrammetry, Remote Sensing and Spatial Information Sciences, 41, pp.675-683.

Nex, F.C. and Rinaudo, F., 2011. LiDAR or Photogrammetry? Integration is the answer. Rivista Italiana di Telerilevamento, 43(2), pp.107-121.

Nocerino, E., Menna, F., Remondino, F., Beraldin, J.A., Cournoyer, L. and Reain, G., 2016. Experiments on calibrating tilt-shift lenses for close-range photogrammetry. International Archives of the Photogrammetry, Remote Sensing \& Spatial Information Sciences, 41.

Remondino, F., 2011. Heritage recording and 3D modeling with photogrammetry and 3D scanning. Remote Sensing, 3(6), pp.1104-1138.

Remondino, F., Menna, F., Koutsoudis, A., Chamzas, C. and ElHakim, S., 2013, October. Design and implement a reality-based 3D digitisation and modelling project. In Digital Heritage International Congress (DigitalHeritage), 2013 (Vol. 1, pp. 137144). IEEE.

Remondino, F., Rizzi, A., Barazzetti, L., Scaioni, M., Fassi, F., Brumana, R. and Pelagotti, A., 2011. Review of geometric and radiometric analyses of paintings. The Photogrammetric Record, 26(136), pp.439-461.

Remondino, F., Spera, M.G., Nocerino, E., Menna, F. and Nex, F., 2014. State of the art in high density image matching. The Photogrammetric Record, 29(146), pp.144-166.

Ultraviolet Lamp, Cultural Heritage open source, https://chsopensource.org/ultraviolet-lamp/, accessed on April 2018

Verri, G. and Saunders, D., 2014. Xenon flash for reflectance and luminescence (multispectral) imaging in cultural heritage applications. The British Museum Technical Bulletin, 8, pp.8392.
Vak, B., 2013. Auf der Suche nach dem Original. Trinkl, E. (ed.), Interdisziplinäre Dokumentations- und Visualisierungsmethoden, Wien, pp. 41-72.

Zimmermann-Elseify, 2017. Corpus Vasorum Antiquorum Deutschland, Band 102. Antikensammlung Berlin Band 17: Attisch schwarzfigurige Lekythen. C. H. Beck, München 2017, ISBN 978-3-406-71541-9. 